\title{
Stock portfolio hedging with financial options
}

\author{
Juan Andrés Jaramillo-Restrepo ${ }^{1}$, Miguel Jiménez-Gómez ${ }^{2}$, Natalia Acevedo-Prins ${ }^{3}$ \\ ${ }^{1,2}$ Facultad de Minas, Universidad Nacional de Colombia, Colombia \\ ${ }^{2,3}$ Facultad de Ciencias Económicas y Administrativas, Instituto Tecnológico Metropolitano - ITM, Colombia
}

\begin{tabular}{lll}
\hline \hline Article Info & ABSTRACT \\
\cline { 2 - 3 } $\begin{array}{l}\text { Article history: } \\
\text { Received Dec 2, 2019 }\end{array}$ & $\begin{array}{l}\text { The financial market currently offers derivative products whose } \\
\text { characteristics allow investors to reduce the negative impact of natural } \\
\text { mevised Mar 6, 2020 } \\
\text { Accepted Mar 26, 2020 }\end{array}$ & $\begin{array}{l}\text { options is one of the possible strategies that an investor can implement in } \\
\text { order to reduce the exposure or risk of their investments. This paper aims to } \\
\text { assess the real impact of financial options as a hedging instrument on an } \\
\text { investment portfolio made up of variable income assets of the Colombian } \\
\text { market. The results show that for options with an upward trend, call options } \\
\text { allow future losses to be hedged; on the other hand, for bearish trends, } \\
\text { coverage is made with put options. }\end{array}$ \\
$\begin{array}{l}\text { Financial options } \\
\text { Geometric brownian }\end{array}$ & motion
\end{tabular}

Copyright $\odot 2020$ Institute of Advanced Engineering and Science. All rights reserved.

\section{Corresponding Author:}

Miguel Jiménez-Gómez, Instituto Tecnológico Metropolitano - ITM,

Universidad Nacional de Colombia,

Calle 54 A \#30-01, Medellín, Colombia.

Email: luisjimenez@itm.edu.co

\section{INTRODUCTION}

The financial hedging activities, whose main objective is to reduce investment risk, reduce the volatility of corporate profits. It is common to find companies that cover, through the use of financial derivatives, activities in the balance sheet [1-2]. There are studies that support the use of financial instruments as hedging instruments, for example; Bartram, Brown, and Minton [3], conducted a study that allowed hedges to mitigate exposure to exchange risk, as a result indicate that hedges can be reduced up to $40 \%$ of exposure, thus, companies should not only be covered operationally but also on its financial results. Another benefit of the coverage is presented by Fok, Carroll, and Chiou [1] who argue that covering a company generates less volatility in profits; however, they improve the value of the company because the coverage reduces the likelihood of financial problems, reduces the costs of the debt agency and reduces some equity costs. Ulusoy \& Onbirler [4] for their part indicate that it is the use of options together with futures in the case of cash flows and that they are already stabilized.

The studies presented and more common, are focused on the risk that multinational companies have when exposed to exchange rates, however, hedges are also useful when exposed to market risk when there is an investment in the stock market. Chung, Liu, \& Tsai [5], carry out the first study on the impact that derivative hedging strategies have on the underlying shares. Based on the investor's problem, Echaust [6], performs a study where it presents an adequate coverage strategy problem in the expected profit model when forward contracts and option strategies are available. Within its main finding, it argues that a hedging strategy is well designed, when it completely eliminates the risk and does not create another risk for the investor; However, the best strategy does not exist in all circumstances and each of the strategies considered can guarantee high coverage effectiveness. The characteristics of the financial options position it, for various authors, as the best instrument to manage risk, because the mechanics of this type of contracts allow to 
transfer the risk of losses, but at the same time the opportunities to obtain a benefit in case there is a positive evolution of prices [7].

The risk is the possible direct or indirect loss of cash flows [8]; therefore, financial institutions charge an interest for these resources, which is the reward received for the risks assumed, in addition to guaranteeing that their money does not lose value over time. Companies also need cash flows to finance their operation, working capital, expansion, settlement of liabilities among others. For this type of needs, the stock market has instruments such as the shares that are used to finance equity and liabilities bonds, for both markets there is a place where the holders of these securities can negotiate them, either for short or long term operations. long. People invest in the stock market through collective investment funds created by companies in the financial sector that, with the help of specialists, develop portfolios according to the profiles of their clients, a service that is remunerated through commissions. Not everyone finds affinity with these funds and their costs; Therefore, independently decide to invest according to their capital and time of return, this is where risk becomes a decisive factor in shaping a portfolio, in order to optimize the distribution between risk and [9].

The acquisition of several shares can generate a decrease in exposure to the factors of each company, non-systematic risk. The limit of the risk reduction through diversification reaches the variables that are foreign to the company (systematic), where all receive exposure to the risks of each country and common macroeconomic issues, gaining importance its quantification with the Beta coefficient of the model CAPM, as well as the VaR (Value at Risk) [10], which is a measure that allows identifying the maximum loss of a capital exposed in a period of time $t$ with a level of confidence $Z \%$ [8], where volatility of prices can cause strong gains or losses, which are qualities of market risk [11]. This situation, coupled with the weakening of systematic risk with the diversification of assets, makes those interested in investing in stocks vulnerable and unable to avoid price volatility and thereby endangering their assets; becoming attractive any measure that is in favor of guaranteeing a minimum devaluation of a portfolio, where the coverage with financial derivatives take a leading role as a measure to reduce said exposures [12].

The financial instruments used to hedge are financial futures and options. Hedging strategies with financial options for portfolios are more flexible and have greater benefits than financial futures because they do not require an initial margin [13]. Financial options are widely used to manage market risk in investment portfolios [14-18]. The options are usually a very used instrument to carry out these operations, because they allow to take short positions on assets that are on the downside, allowing to compensate the losses. Complementing the aforementioned [19] in a study conducted with several investment funds shows that the strategy of using options is aimed at counteracting the high levels of portfolio risk, as well as the acquisition of put is linked to a lower level of systematic risk; leading to a limitation on additional losses. On the other hand, [20], it shows that the mutual investment funds that make hedges with options have a higher return adjusted to the risk and their systematic component is significantly lower than those that lack it, for that reason the options as a hedging instrument generate a lower standard deviation, higher Sharpe ratios and returns with respect to others. exhibitions. Therefore, an investment that is not covered by an option or other asset, will generate greater exposure to market risk, its occurrence being unfavorable in a period of crisis, where the risk increases significantly while the returns react at a lower rate or negative, whereas at the time when the market is strengthened, its risk will not be as high and the good choice of assets to be included in the portfolio will be considered important [19]

Therefore, the main objective of this study is to assess the impact of financial options as a hedging instrument on portfolios of shares of the Colombian market, seeking mitigation of market risk. Therefore, a hedging strategy with financial options will be designed for a portfolio of actions, which will be valued using the Black-Scholes method, binomial trees and Monte Carlo simulation. It will also seek to simulate the price of the shares with the use of the Geometric Brownian Motion (GBM); all this, in order to evaluate quantitatively the benefit of the coverage with financial options for a portfolio of shares of the Colombian market. Thus, the article presents, in the first instance, a theoretical approach to financial options and their valuation methods, then the methodology to be addressed is explained, and finally, the results found in the Colombian portfolio are presented.

\section{RESEARCH METHOD}

With the objective of evidencing the impact of the realization of a hedge through financial options in the Colombian market, the two shares with the highest trading volume historically in the Colombian stock market, which would be preferred by Bancolombia and Ecopetrol, were chosen. Then, for the valuation of stock options, a discount rate was calculated that demonstrates the opportunity cost of money in the market, based on the Banking Reference Index (IBR). As its official report is for 1, 3 and 6 months, the Bootstrap method was used to obtain the 2, 4 and 5-month rates; with the information thrown, simulations of the behavior of the underlying asset were carried out. 
After obtaining the possible behavior of the asset, we proceeded with the calculation of the premiums of the financial options, in this case, we used monthly breaks, that is, $\Delta t=1,2, \ldots, 6$, based on the GBM we proceeded with the calculation of the price of the underlying in each $\Delta t$, to determine the compensation obtained with the options. We continued with obtaining the price with coverage and the premium for each type of option studied. The price of the underlying asset with coverage and premium was obtained. By means of the Montecarlo simulation method, 50,000 stock price scenarios were calculated, both with and without coverage, with these data averages and percentiles were obtained to know the risk associated with the market and the capacity of the options to mitigate it.

\subsection{Financial options}

Financial options are a financial instrument that grants a right to the buyer and an obligation to the seller to carry out a transaction under previously established price and date conditions [21]. Buyers of the options must pay the seller a premium. Call options exist which means acquiring the right to buy an asset on a date and at a previously established price and options Put grants the right to sell an asset on a specific date in the future and at a certain price [19].

\subsection{Options valuation methods}

Multiple options valuation models have been developed, based on the model proposed by Black and Scholes, much more complex models have emerged that consider the stochastic nature of volatility, discontinuity and other factors. In addition to this, other numerical methods such as Monte Carlo simulation and binomial trees are added. The Black-Scholes method consists of an equation used in financial mathematics to determine the price of financial assets. It is based on stochastic process theory to understand and model price behavior as a Wiener process or Standard Brownian movement. The main assumptions of the model are: The price of the asset follows a logarithmic normal distribution, so the returns are normally distributed. The value of the returns is known and is directly proportional to the passage of time. There are no transaction costs, so you can establish a risk-free coverage between the asset and the option at no cost. The interest rates are known and constant. During the exercise period, the underlying share will not pay dividends. Finally, the options are European type [22].

The equation that describes the Black-Scholes model is [23]:

$$
c=\left[N\left(d_{1}\right) * S_{0}\right]-\left[N\left(d_{2}\right) * k e^{-r t}\right]
$$

where:

$$
\begin{aligned}
& d_{1}=\frac{\operatorname{Ln}\left(\frac{S_{0}}{K}\right)+\left(r+\frac{\sigma^{2}}{2}\right)}{\sigma * \sqrt{t}} \\
& d_{2}=d_{1}-\sigma \sqrt{t}
\end{aligned}
$$

c: Current value of the option

t: Time in which the right can be exercised, measured in years.

r: Annual risk-free rate.

S0: Price of the underlying.

$\mathrm{k}$ : Price of the year.

$\mathrm{N}(\mathrm{d} 1)$ : Probability value in a normal distribution for the point $\mathrm{d} \_1$ obtained.

$\mathrm{N}$ (d2): Probability value in a normal distribution for the point $\mathrm{d} \_2$ obtained.

$\sigma$ : Standard deviation or volatility of an action.

On the other hand, binomial trees are based on the calculation of the probability distribution used by the different market agents to value options with a similar maturity on the same underlying asset and based on this, the process followed by the price of the active, all this under the multiplicative binomial structure, where the volatility in each node depends on the different probabilities of transition in each of them. If the validity of an option on an asset that does not pay dividends, whose initial price is S0 and the strike price is k, is divided into $\mathrm{N}$ intervals of length $\Delta \mathrm{t}$. It is defined to $f_{j}^{(i)}$, as the value of the option in the node $(\mathrm{i}, \mathrm{j})$ that will depend on the nature and characteristics of the option [24].

In the case of a call option, the value on its due date is given by $f_{j}^{(N)}=\max \left(S_{t}-k, 0\right)$ and when you have a put option, it will be $f_{j}^{(N)}=\max \left(k-S_{t}, 0\right)$. 


$$
S_{t}^{(i)}=S_{0} * \prod_{k=1}^{j-1} u_{k}^{(k-1)} * \prod_{k=1}^{i-j+1} u_{k}^{(i-k)}
$$

It is important to remember that the values of the options in each node must be discounted at a riskfree rate $r$ in order to know the present value of this position.

Finally, the Monte Carlo Simulation method has origins in Monaco, around 1944, hence its name. Its first real use was in the development of the atomic bomb during World War II. The objective was to simulate the diffusion of random neutrons in a diffusion medium. The method is based on the systematic sampling of random variables and the algorithm that governs it follows the following order:

a) Determine the Random Variable and its accumulated distributions.

b) Iterate as many times as samples are needed.

c) Calculate mean, standard deviation.

d) Analyze results for different sample sizes.

To correctly implement this method, it is necessary to bear in mind that the system must be described by one or more probability distribution functions, the way in which the random numbers are generated should be adequate in such a way that there is no correlation between them, you must define the limits for which the values of the random variable make sense, with what error you will work or how much is acceptable [25].

The Monte Carlo simulation aims to create a mathematical model of a process that is either stochastic or probabilistic, identifying those variables (inputs) whose random behavior determines the overall behavior of the process. When the input or random variables are identified, an experiment is carried out, which consists in generating random samples for said inputs in order to analyze their behavior. Once this experiment is repeated $n$ times, there are $n$ observations of the process which gives a clearer idea of its operation. defined by:

The GBM, applied to model the price of an underlying asset to a financial options position is

$$
S_{t+\Delta t}=S_{t} e^{\left[\left(\mu-\frac{\sigma^{2}}{2}\right) \Delta t+\sigma \sqrt{\Delta t} \varepsilon\right]}
$$

where:

$t$ : Time in which the right can be exercised, measured in years.

$\mu$ : Mean logarithmic performances.

$S_{t}$ : Price of the underlying in time t.

$\sigma:$ Standard deviation of logarithmic performance.

$\varepsilon$ : Random variable that is distributed normal with zero means and variance one.

\section{RESULTS AND ANALYSIS}

Hedge was made through financial options in the local market, for which the two stocks with the highest volume of historical trading in the Colombian stock market were chosen. For this, it was necessary to extract the historical of the daily negotiations of each of the actions, then a monthly filter was applied on the closing prices in each period, and finally a statistical summary of the behavior of the actions in a period was made. comprised between March 31, 2014 and March 31, 2018. The results obtained are summarized in Table 1 and additionally, Figure 1 shows the behavior of both actions in this same period of time, where contrary behaviors are reflected, that is, while Bancolombia's preferential share presents a positive average, the average of Ecopetrol's stock is negative, in addition to this, the deviation of the latter is greater than that of Bancolombia, which is why the risk assumed by a Investor when buying Ecopetrol is greater than if you bought the Bancolombia Preferential.

After analyzing the behavior of the stocks to be studied, the calculation was carried out at a suitable rate for the discount and calculation of the value of the underlying assets, for which reason the IBR was taken as a basis, which is reported by the Bank of the Republic for 1, 3 and 6 months; However, for the purpose of this study, the rates for 2, 4 and 5 months are required, so it was necessary to use the Bootstrap method to achieve these. Table 2 shows the values obtained.

Figure 2 is the result of the Monte Carlo simulation of Bancolombia's share price for a six-month projection. It is evident that in the application of the Brownian Geometric Motion the variance increases over time; however, the average price remains constant. The average price is the expected value of the Bancolombia share for each of the months and the percentiles of $2.5 \%$ and $97.5 \%$ are a $95 \%$ confidence interval. 
Table 1. Statistical summary for PFBCOLOM and ECOPETROL

\begin{tabular}{lll}
\hline & PFBCOLOM & ECOPETROL \\
\hline Average $(\mu)$ & 0.006 & -0.016 \\
Standard deviation $(\sigma)(\%)$ & 6.02 & 8.01 \\
S0 $($ March 31, 2018) $(\mathrm{COP})$ & 29,000 & 1,665 \\
\hline
\end{tabular}

Table 2. Discount rate from IBR

\begin{tabular}{cc}
\hline Months & Continuous rate \\
\hline 1 & $6.54 \%$ \\
2 & $6.48 \%$ \\
3 & $6.42 \%$ \\
4 & $6.36 \%$ \\
5 & $6.31 \%$ \\
6 & $6.25 \%$ \\
\hline
\end{tabular}

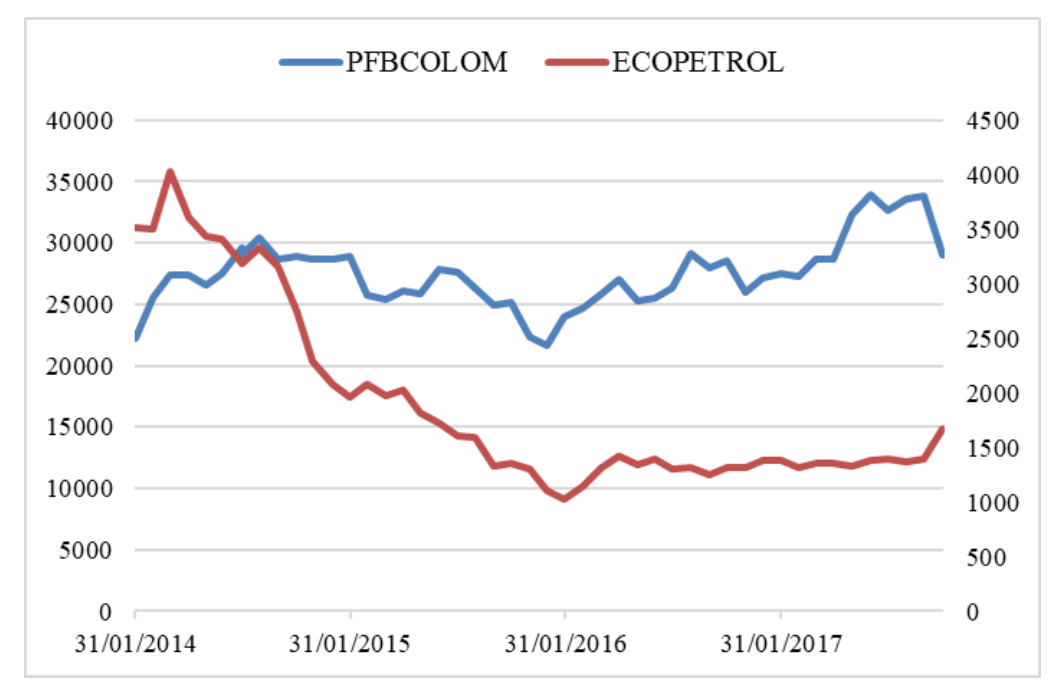

Figure 1. Performance share prices

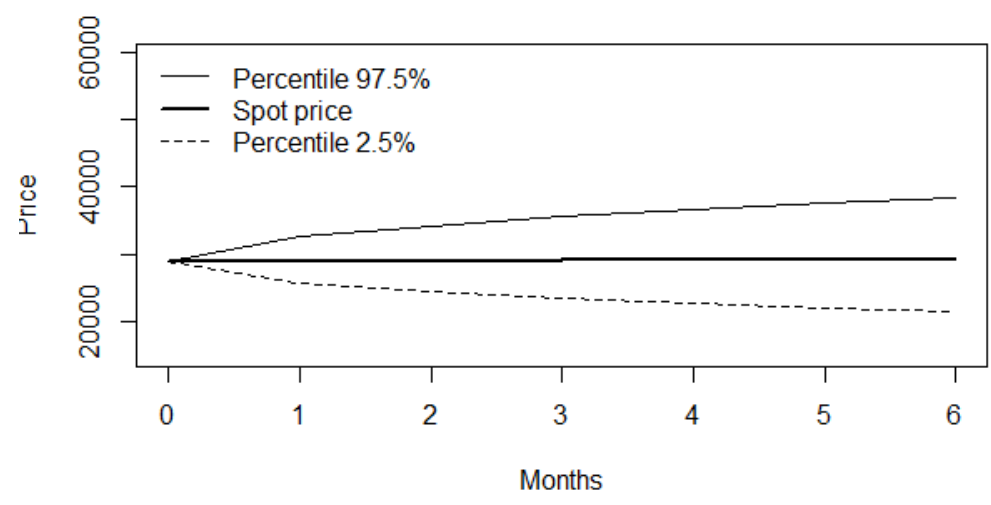

Figure 2. Expected behavior of the price of Bancolombia's preferred share

Also, it is important to highlight that the volatility of the simulated prices increase the first month of analysis; the difference between the percentiles and the price without coverage is lower than that presented in the following months; however, this difference between the two percentiles is symmetric throughout the period analyzed. As explained above, when an investor decides to buy a put option, he is covering a downward trend in the price of the asset and, on the other hand, when he has a call option, the investor is covering himself before possible rises in the price of the underlying stock. The hedged price of the PFBCOLOM share is shown in Figure 3. The chart on the left is the result of the Monte Carlo simulation for the coverage of the buyers of the stock and the chart on the left is the result for sellers. Like Figure 2, in Figure 3 the variance increases over time and the price average remains constant, but there is no symmetry because the right acquired by the financial options allows the investor to exercise only in one scenario. Therefore, the average price is closer to a percentile.

In this case, it would be advisable to make a hedge with put options, since with them a higher price would be obtained for the sale of this asset, thus increasing the profit margin obtained. The purchase options 
would not be adequate since the price obtained when a cover of this type is made is greater than the price expected to present the action in each of the six months analyzed, it is more beneficial to buy the shares at the price of market that exercise the right to purchase. On the other hand, for the action of ECOPETROL the same process and previous analysis was carried out, in Figure 4 the behavior of prices without coverage for each month is presented, in addition, the percentiles of $97.5 \%$ and 2 are shown, $5 \%$. As in the case analyzed above, it should be noted that the volatility of the estimates made under this model increases; In the first month of analysis, the difference between the percentiles and the spot price without coverage is lower than that presented in the following months, however, this difference is symmetric throughout the period studied.
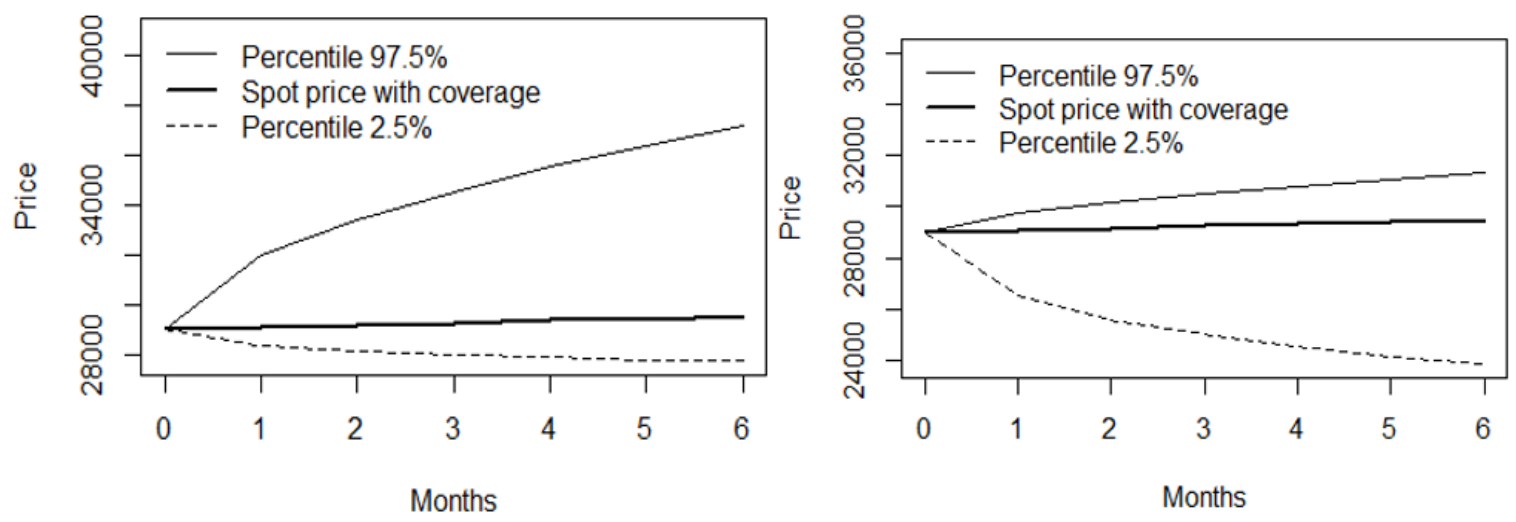

Figure 3. Spot price PFBCOLOM with put and call hedge

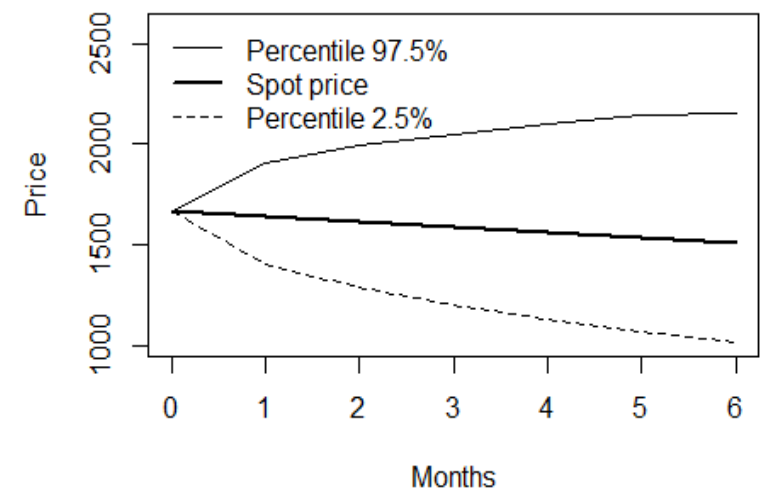

Figure 4. Expected behavior of the share price of ECOPETROL

Likewise, the assumptions used for $\mathrm{t}=0$ are presented in Table 1 , the strike price for the ECOPETROL options was set at 1,665 COP (equal to the last price of October 31, 2017). From this, the prices of the following six months were projected, Table 3 summarizes the results obtained, there it is observed that the 7.8 percentage points corresponds to a change of approximately - $127 \mathrm{COP}$ in the value of this asset.

Bearing in mind that there is a bearish outlook for the behavior of the underlying asset, it is advisable to hedge using European put options since with this protection strategy a sale price higher than the market price would be obtained in each of the six months analyzed. The losses that an investor could have in his portfolio include this asset will be compensated totally or partially by the profits obtained under this type of hedging strategy. The coverage with the ECOPETROL share is shown in Figure 5. Figure 5 has a similar behavior to Figure 3 because the same hedging strategy was carried out with financial options. The mean price remains constant and is close to one percentile than the other, which means that the probability distribution of the results is not symmetric in time. The percentile farthest from the average indicates that the investor may have better prices with coverage with financial options. 


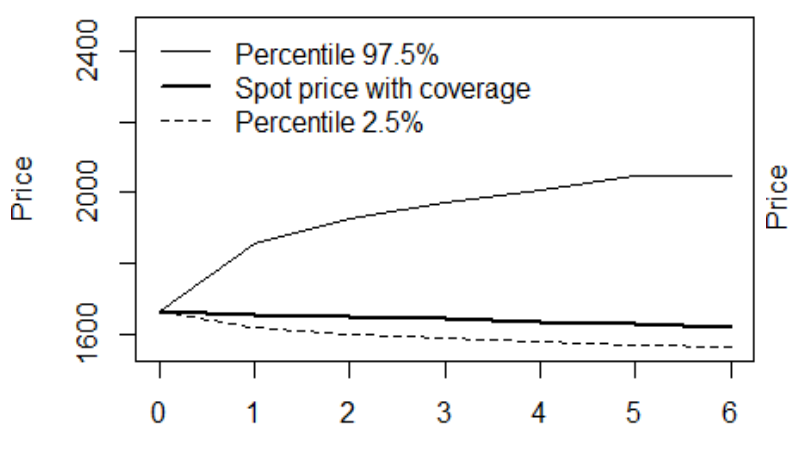

Months

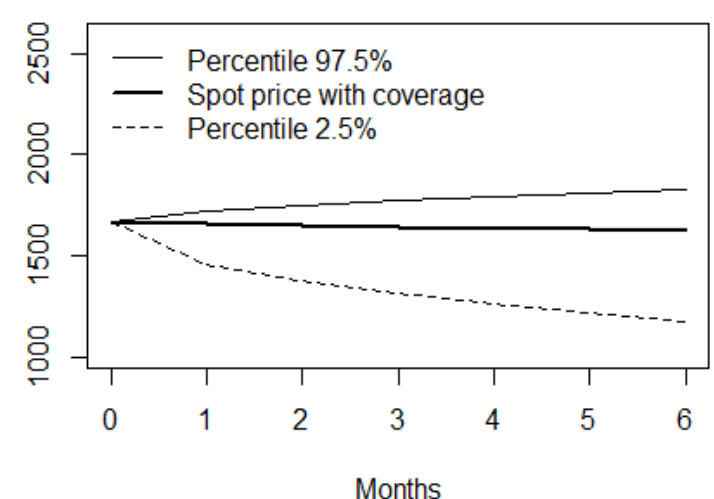

Months

Figure 5. Spot price ECOPETROL with put and call hedge

\section{CONCLUSION}

Coverage is made with options for the Ecopetrol and Preferencial Bancolombia shares to mitigate the risk associated with movements in share prices. The coverage is made from the perspective of the owners of the shares, so put options were used. The put options are appropriate when the asset is owned and will be sold at some future date, that is, the put options collect the sales of the assets.

To determine the benefits of the coverage with the options, the stock prices were modeled with the Geometric Brownian Movement (GBM) and, applying Monte Carlo simulation, results were obtained for the non-hedged and hedged scenarios. The results showed that prices without coverage are more volatile as time passes, giving justification for the realization of coverage because the risk increases. With the options, the results showed that also as time passes, the risk increases because the rank between the percentiles increases; however, these results are less volatile than the results without coverage. The foregoing demonstrates the benefit of using the options for hedging purposes, the risk is mitigated.

It is emphasized that with modeling and simulation the results have similar behavior when only the spot price is used. Each simulated period has a symmetric distribution where the average of the prices is located in the center of the data. On the other hand, with the results with coverage the same thing does not happen. The average price is located with a trend towards one of the percentiles, with put options approaching the $2.5 \%$ percentile and with call options at the $97.5 \%$ percentile.

\section{REFERENCES}

[1] R. C. W. Fok, C. Carroll, and M. C. Chiou, "Determinants of Corporate Hedging and Derivatives: A Revisit," J. Econ. Bus., vol. 49, pp. 569-585, 1997.

[2] W. Guay and S. P. Kothari, "How much do firms hedge with derivatives?," J. financ. econ., vol. 70, no. 3, pp. 423461, 2003.

[3] S. M. Bartram, G. W. Brown, and B. A. Minton, "Resolving the exposure puzzle: The many facets of exchange rate exposure," J. financ. econ., vol. 95, no. 2, pp. 148-173, 2010.

[4] V. Ulusoy and Ö. Onbirler, "Marginal speculation and hedging in commodity markets," Financ. Res. Lett., vol. 23, pp. 269-282, 2017.

[5] S. L. Chung, W. R. Liu, and W. C. Tsai, "The impact of derivatives hedging on the stock market: Evidence from Taiwan's covered warrants market," J. Bank. Financ., vol. 42, no. 1, pp. 123-133, 2014.

[6] K. Echaust, "How firms can hedge against market risk," Stud. Logic, Gramm. Rhetor., vol. 37, no. 50, pp. 39-49, 2014.

[7] I. D. Ochoa and C. González, "Evaluación del mercado de opciones sobre tasas de cambio: Perspectivas para una mejor utilización," Rev. EIA, vol. 7, pp. 145-158, 2007.

[8] M. Papaioannou, "Exchange rate risk measurement and management: Issues and approaches for firms," 2006.

[9] T. Choudhry, "Short-run deviations and time-varying hedge ratios: Evidence from agricultural futures markets," Int. Rev. Financ. Anal., vol. 18, pp. 58-65, 2009.

[10] S. Álvarez-díez, E. Alfaro-cid, and M. O. Fernández-blanco, "Hedging foreign exchange rate risk: Multi-currency diversification,” Eur. J. Manag. BusinessEconomics, vol. 25, pp. 2-7, 2016.

[11] A. De Lara Haro, Medición y control de riesgos financieros. México: LIMUSA, 2009.

[12] P. Jorion, "International portfolio diversification with estimation Risk.," J. Bus., vol. 58, pp. 259-278, 1985.

[13] W. G. Zhang, X. Yu, and Y. J. Liu, "Trade and currency options hedging model," J. Comput. Appl. Math., vol. 343, pp. 328-340, 2018.

[14] M. C. Chuang, C. H. Wen, and S. K. Lin, "Valuation and empirical analysis of currency options," Int. Rev. Econ. Financ., vol. 66, no. November 2019, pp. 71-91, 2020. 
[15] K. H. Kim, N. U. Kim, D. C. Ju, and J. H. Ri, "Efficient hedging currency options in fractional Brownian motion model with jumps," Phys. A Stat. Mech. its Appl., vol. 539, p. 122868, 2020.

[16] J. Fletcher and A. Marshall, "An empirical examination of the benefits of international diversification," J. Int. Financ. Mark. Institutions Money, vol. 15, no. 5, pp. 455-468, 2005.

[17] M. Barjaktarović, D. Karic, and R. Zecevic, "Currency options in function of currency risk hedging and speculating,” Econ. Anal., vol. 44, no. 2, pp. 38-46, 2011.

[18] J. F. Solomon and N. L. Joseph, "Which corporate hedging motives are appropriate? An institutional shareholders' perspective," Int. J. Financ. Econ., vol. 5, pp. 339-347, 2000.

[19] E. Namvar, B. Phillips, K. Pukthuanthong, and P. Raghavendra Rau, "Do hedge funds dynamically manage systematic risk?," J. Bank. Financ., vol. 64, pp. 1-15, 2016.

[20] M. Natter, M. Rohleder, D. Schulte, and M. Wilkens, "The benefits of option use by mutual funds," J. Finan. Intermediation, vol. 26, pp. 142-168, 2016.

[21] L. JIMÉNEZ, N. ACEVEDO, and M. ROJAS, "Valoración de opción real en proyectos de generación de energía eólica en Colombia," Espacios, vol. 37, no. 26, p. 26, 2016.

[22] J. Hull, Options, futures, and other derivatives, 8th ed. Boston: Pearson Education, 2012.

[23] H. Kleinert and J. Korbel, "Option pricing beyond Black - Scholes based on double-fractional diffusion," Physica A, vol. 449, pp. 200-214, 2016.

[24] R. McDonald, Derivatives Markets, 3rd ed. New Jersey: Pearson Education, 2013.

[25] L. Jiménez, N. Acevedo, and N. Castaño, "Cobertura cambiaria por medio de instrumentos derivados para empresa exportadora de flores en Colombia,” En-Contexto, vol. 4, no. 5, pp. 119-138, 2016. 